\title{
Examination of the Stability of Amoxicillin in Compounded Suppositories and Ointments
}

\author{
Małgorzata Zdzieborska, Ewa Siedlecka and Izabela Orłowska \\ Department of Applied Pharmacy and Bioengineering, Medical University of Warsaw, Poland
}

\begin{abstract}
We examined the stability of amoxicillin trihydrate from the preparation Augmentin in compounded forms of drugs such as vaginal suppositories and ointments. The quantity of the antibiotic in the preparations studied was determined directly after they had been made and after a lapse of 7 and 14 days. We also carried out comparative examinations of the stability of sodium amoxicillin (Tarommentin) and sodium ampicillin (Ampicillin) in ointments with an addition of a boric acid solution. The examinations confirmed the stability of amoxicillin trihydrate in suppositories and in anhydrous and hydrated ointments. The content of this antibiotic in ointments with an addition of a boric acid solution decreases slightly. Comparative studies of the stability of sodium amoxicillin and sodium amoxicillin revealed a markedly lower stability of the two antibiotics in comparison to the stability of amoxicillin trihydrate.
\end{abstract}

Key words: Amoxicillin, ampicillin, vaginal suppositories, ointments, stability

\section{Introduction}

$\beta$-lactam antibiotics are, next to macrolides, the group of antibiotics most frequently prescribed in outpatient health care. This is a consequence of their broad spectrum of action and considerable therapeutic effectiveness with a simultaneous safety of use [1]. The principal antibiotic of this group, i.e. the most frequently recommended and applied, is amoxicillin [2, 3]. Amoxicillin, a semi-synthetic penicillin, is an antibiotic of an antibacterial action. The mechanism of its action consists in blocking enzymes responsible for the biosynthesis of peptidoglycan, an element indispensible in the construction of the bacterial cellular wall [4]. Amoxicillin has a broad spectrum of antibacterial action. As the antibiotic can be decomposed by bacterial $\beta$-lactamases, it is applied in combination with clavulanic acid. The ratio of the two active ingredients in the preparations used in therapy can vary, this being clinically justified in terms of the effectiveness of the therapy and reduction of side effects in patients [5].

Corresponding author: Ewa Siedlecka Ph.D., graduated faculty of Pharmacy Medical Academy in Warsaw, research field: drugs technology.
The amoxicillin and clavulanic acid-containing therapeutic products available on the Polish market include oral preparations Augmentin and Amoxiklav and Taromentin, a preparation for making solutions for infusions and injections. According to the Summary of Product Characteristics, Augmentin is a preparation intended for oral or intravenous administration. It shows high activity against numerous microbes Hemopilus influenze, Moraxella catharralis, Enterococcus faecalis, Gardnerella vaginalis, Streptococcus agalatiae, Streptococcus pyogenes, Bacteroides fragilis. It is applied in the treatment of upper and lower respiratory infections, urinary tract infections and borreliosis. Augmentin is recommended to be used in recurrent pharyngitis and tonsillitis, otitis media and sinusitis treated in an outpatient setting as well as in community acquired pneumonia in children and adults $[6,7]$. It is also recommended to be used in combination with other antibiotics in the treatment of COPD exacerbation and nosocomial pneumonia $[8,9]$. Amoxicillin is also administered in the treatment of urinary tract disorders, most frequently in the inflammation of the urinary bladder, urethra and pyelonephritis [10, 11]. Augmentin is also used in 
gynaecology in the treatment of bacterial conditions developing within pelvis minor. Bacteria responsible for infections within the vulva can proceed from the urinary system and from the colon. They include primarily bacteria of the type of Escherichia coli, Klebsiella sp., Enterococcus faecalis and Staphylococcus saprophyticus. Infections of this kind can prove particularly dangerous as their neglect can lead to infertility and ectopic pregnancy [12]. Infections can also be caused by sexually transmitted Chlamydia trachomatis. The activity of amoxicillin against this pathogen has been revelated in vivo, in spite of no such an action in vitro [13]. The Augmentin therapy of Chlamydia trachomatis-induced infections is effective in approximately $80 \%$ of cases, especially in the treatment of pyelonephrits [8]. Due to its high activity against both aerobic and anaerobic microorganisms Augmentin is effective in the treatment of mixed infections. It is used in patients with urinary tract infections accompanied by gynaecological conditions [10].

What is of particular importance in antibiotic-containing drugs is to obtain a therapeutic concentration of the substance to be active in the place of the infection and a proper mode of the drug administration. The antibiotic should reach the infected tissue in an active form. Too low blood and tissue concentration of the antibiotic is responsible for the absence of a therapeutic effect as well as for the development of microbial resistance. Another crucial problem is the stability of the antibiotic in a given form of the drug. A compounded drug should be made and packed so as to ensure the stability of the active substance throughout the period of its application by the patient. Antibiotics are sensitive to a multitude of factors such as temperature, light, presence of metal ions, environment reaction and enzymes produced by microbes [14]. Consequently, it is crucial to determine the stability of the antibiotic-containing compounded forms of drugs. This is of particular importance in case of antibiotics being penicillin derivatives. According to literature [4] semi-synthetic penicillins are antibiotics of limited stability. The $\beta$-lactam bond breaks in both acidic and alkaline environment resulting in therapeutically inactive products [13].

The quantitative and qualitative analysis of compounded drugs prepared in selected Warsaw pharmacies which we carried out showed that in 2010 recipes containing amoxicillin or its combination with clavulanic acid accounted for approximately $25 \%$ of prescriptions for tablets and suppositories. In addition, the analysis showed that amoxicillin and also ampicillin were found in the composition of compounded ointments. As the antibiotics do not appear in the form of a pro receptura substance, industrial preparations, such as oral tablets or injectable preparations, had to be used to prepare a given form of the drug. The use of such preparations to obtain the form of the drug to be adequate for local, external (vaginal suppositories and dermatological ointments) means that we have to do with the off-label application of these therapeutic products, application not specified in the registration indications as the mode of application and administration of the preparations is not specified in the Summary of Product Characteristics. Consequently, we do not have at our disposal any data concerning the stability of amoxicillin in these forms of the drug. As a result and also because of the presence in the prescribed compounded drugs of auxiliary substances which can affect the stability of amoxicillin (presence of boric acid, water), a decision was made to carry out a study of the stability of the antibiotic in compounded drugs made with the use of industrial preparations.

\section{Materials and Reagents}

The study involved the use of the following therapeutic products: Augmentin coated tablets containing $500 \mathrm{mg}$ of trihydrate amoxicillin and 150 $\mathrm{mg}$ of clavulanic acid of GlaxoSmithKline Export (Series No. 552260), expiry date) September 2013; Taromentin powder for the preparation of infusion 
solutions composed of $500 \mathrm{mg}$ of sodium amoxicillin and $125 \mathrm{mg}$ of clavulanic acid (Series No. 101111), expiry date November 2013; Ampicillin powder for the preparation of injectable solutions containing $500 \mathrm{mg}$ of sodium amoxicillin, manufactured by Polfa Tarchomin (Series No. 2010112), expiry date January 2015. The following auxiliary substances were also used: Vaselinum flavum (F.P. Hasco-lek S.A., PL), Lanolinum anhydricum (Caelo Cesar \& Lorets GMBH), Oleum cacao (Pharma Cosmetics, PL), Acidum boricum (Pharma Cosmetics, PL), Paraffinum Liquidum (Aflofarm, PL), Lactosum (lactose monohydrate PhE., Pharma Cosmetics, PL) and Aqua pro iniectione (solvent for the preparation of parenteral drugs, Baxter, PL).

The study involved also the use of the following reagents prepared directly before the analyses according to the recipes given in Polish Pharmacopea IX: phosphate buffer of $\mathrm{pH} 7.4$ and acetate buffer of $\mathrm{pH}$ 4.4. Their preparation involved the use of potassium dihydrogen phosphate (Xenon Łódź, PL) and acetic acid (Polskie Odczynniki Chemiczne, PL). We also used $1 \mathrm{~mol} / \mathrm{L}$ solution of hydrochloric acid (hydrochloric acid 35-38\%, pure HCL- $36.46 \mathrm{~g} / \mathrm{mol}$, Chempur, PL), $1 \mathrm{~mol} / \mathrm{L}$ solution of potassium hydroxide (potassium hydroxide pure $\mathrm{KOH}-56.11$ $\mathrm{g} / \mathrm{mol}$, Chempur, PL), $0.01 \mathrm{~mol} / \mathrm{L}$ solution of sodium trisulphate (sodium trisolphate, Polskie Odczynniki Chemiczne S.A., PL) and $2 \%$ starch mucilage.

\subsection{Preparation of Samples}

The suppositories were prepared on the basis of cocoa butter, the ingredients being poured into a mould according to the following composition:

Rp.

$\begin{array}{ll}\text { Augmentin } & 0.5 \\ \text { Lactosi } & 0.2 \\ \text { Ac. Borici } & 0.2 \\ \text { Ol. Cacao } & \text { q.s. }\end{array}$

M.f.glob.vag.

Vaginal suppositories of 3.0 mass were made. The quantity of the powdered tablet mass corresponding to the antibiotic content in the recipe was weighed on analytical scales, the tablets having been first powdered in a mortar and sifted through a sieve. The remaining components of the recipe were weighed on technical scales and mixed lege artis with the prepared tablet mass. Solid ingredients were added to the base of the suppository melted in an evaporating dish, stirred and poured into a mould coated internally with liquid paraffin. The mould was placed in a refrigerator where it was kept until the suppository settled. Next, every suppository was weighed. The ready forms of the drug were stored in a refrigerator at the temperature of $5 \pm 3$ ${ }^{\circ} \mathrm{C}$. The mean weight of one suppository was $3.5971 \pm$ $0.09 \mathrm{~g}$.

To make ointment with amoxicillin we used Augmentin. Anhydrous ointments were prepared on a base from yellow vaseline, lanoline and liquid paraffin. Hydrated ointments contained also water or a $3 \%$ solution of boric acid. Amoxicillin from the preparation bearing the trade name Augmentin was used to prepare the drugs.

The ointments were made according to the following compositions:
Ointment 1

Rp.

Amoxycillini

Lanolini

Vaselini flavi

Paraffini liq.

M.f.ung

Ointment 3

Rp.

Amoxycillini 0.625

Lanolini

Vaselini flavi 50.0

Paraffini liq. 50.0

$3 \%$ Sol.Ac.borici 3.0

M.f.ung
Ointment 2

Rp.

$\begin{array}{lll}0.625 & \text { Amoxycillini } & 0.625 \\ 50.0 & \text { Lanolini } & 50.0 \\ 50.0 & \text { Vaselini flavi } & 50.0 \\ 10.0 & \text { Paraffini liq. } & 10.0 \\ & \text { Aqua dest. } & 3.0 \\ & \text { M.f.ung } & \end{array}$

0.0

3.0 
The ingredients of the ointment melted in an evaporator, mixed and cooled down were added to the tablet mass obtained lege artis and prepared as in the case of vaginal suppositories. In case of lotion ointments a hydrous solution of boric acid or a $3 \%$ solution of boric acid were next added. The preparations to be examined were stored in closed packages at the temperature of $5{ }^{\circ} \mathrm{C} \pm 3{ }^{\circ} \mathrm{C}$.

For the purpose of comparison a study of the stability of sodium amoxicillin and sodium ampicillin from Taromentin and Ampicillin preparations, respectively, was also carried out. The ointment was prepared in the same way as in the case of compounded ointments with amoxicillin.

\section{Ointment 4}

Rp.

$\begin{array}{ll}\text { Amoxycillini (Taromentin) } & 0.625 \\ \text { Lanolini } & 50.0 \\ \text { Vaselini flavi } & 50.0 \\ \text { Paraffini liq. } & 10.0 \\ \text { 3\% Sol. Ac.borici } & 3.0 \\ \text { M.f.ung } & \end{array}$

Ointment 5

Rp.

$\begin{array}{ll}\text { Amoxycillini (Taromentin) } & 0.625 \\ \text { Lanolini } & 50.0 \\ \text { Vaselini flavi } & 50.0 \\ \text { Paraffini liq. } & 10.0 \\ \text { 3\% Sol. Ac.borici } & 3.0 \\ \text { M.f.ung } & \end{array}$

\subsection{Method}

The samples prepared for examination contained an equivalent of $200 \mathrm{mg}$ of the antibiotic. The content of the non-decomposed antibiotic was determined with the iodometric method after its extraction, in the form of the drug, with phosphate buffer of $\mathrm{pH}$ 7.4. The determination of the quantity of the antibiotic in the examined preparations (vaginal suppositories and ointments) was made immediately after their execution and after a lapse of 7 and 14 days.

\subsection{Antibiotic Extraction}

Samples containing $200 \mathrm{mg}$ of the antibiotic in the suppository or ointment mass weighed on analytical scales were placed in a beaker of $50 \mathrm{ml}$. Next, $20 \mathrm{ml}$ of phosphate buffer of $\mathrm{pH} 7.4$ were added. The beaker was warmed up in a water bath, the contents being stirred, until the ingredients melted. Next, the contents of the beaker were frozen out to accelerate the coagulation of the solid phase. The water phase was drained on a Munktell filter $\left(65 \mathrm{~g} / \mathrm{cm}^{3}\right.$, Series No. 3.305.110) of $110 \mathrm{~mm}$ pore diameter into a measuring flask of $100 \mathrm{ml}$, and the filter was placed in the beaker and subjected to a repeated extraction with phosphate buffer. The extraction was repeated three times. The eluents collected in the flask were complemented in the flask up to the mark with phosphate buffer.

\subsection{Determination of the Antibiotic Content}

The antibiotic content of the samples was determined with the iodometric method. The method allows to determine quantities of the non-decomposed antibiotic and thus the antibiotic showing a therapeutic action. It makes use of the reaction of iodine with products of its alkaline hydrolysis [13, 14]. Hydrolyzed and control samples were prepared for the examined antibiotic solution simultaneously. The hydrolysis of the antibiotic in the samples studied was performed with a solution of potassium hydroxide, then the samples were neutralized with hydrochloric acid, then acetate buffer $(\mathrm{pH} 4.6)$ and standard iodine solution were added. The samples were left in a place without access of light. After a lapse of 20 minutes surplus iodine was titrated with a standard solution of sodium tiosulphate. Non-hydrolyzed control samples were prepared and determined in the same way as the hydrolysed samples. The percentage content of the non-decomposed antibiotic was calculated with the use of the following formula:

$$
\mathrm{X}=(\mathrm{B}-\mathrm{A}):(\mathrm{b}-\mathrm{a}) \times 100 \%
$$

where: 
$\mathrm{a}$-number of $\mathrm{ml}$ of 0.01 solution of sodium tiosulphate used to titrate the iodine surplus in a hydrolysed sample immediately after its preparation $(\mathrm{t}$ $=0$ )

$\mathrm{b}$-number of $\mathrm{ml}$ of 0.01 solution of sodium tiosulphate used to titrate the iodine surplus in a control sample immediately after its preparation $(t=0)$

A-number of $\mathrm{ml}$ of 0.01 solution of sodium tiosulphate used to titrate the iodine surplus in a hydrolysed sample immediately after a lapse of a specified period of time

$\mathrm{B}$-number of $\mathrm{ml}$ of 0.01 solution of sodium tiosulphate used to titrate the iodine surplus in a control sample immediately after a lapse of a specified period of time

To confirm the usefulness of the method in examining the stability of amoxicillin in compounded forms of drugs, coefficients of variation $\mathrm{V}[\%]$ were calculated for the obtained results of titration determinations.

\section{Results}

The obtained results of the examination of the amoxicillin content in vaginal suppositories and ointments, presented in the tables, are a mean value from the examination of three antibiotic weight samples. A $90 \%$ content of non-decomposed active substance was adopted as the criterion of stability of the antibiotics studied. This value is given in Polish Pharmacopea and European Pharmacopea as the stability level for all active substances. The examinations of the stability of amoxicillin in vaginal suppositories made with the use of the Augmentin preparation carried out within a period of 14 days can be found in Table 1. Their mean content in the samples studied was approximately $100 \% \pm 2 \%$. The obtained results of the examination of the quantity of the antibiotic above $100 \%$ in the examined samples may result from the method used to examine this active substance.

The content of amoxicillin in the anhydrous and hydrated ointments after 7-day storage is presented in Table 2 .

The statistical analysis carried out revealed slight dispersion of titration results. The value of the coefficient of variation did not exceed $10 \%$ which is evidence of statistically insignificant differences in the results of samples obtained. The method can thus be treated as reliable.

\section{Discussion}

Semi-synthetic penicillins, including amoxicillin, are characterized by limited stability [4]. With this group of antibiotics the reaction of the environment is of crucial importance [17]. The stability of amoxicillin in particular forms of the drug is affected not only by the conditions of its execution and storage of the drug but also by the compound in which it appears. Trihydrate amoxicillin is poorly soluble in water, hardly soluble in $96 \%$ ethanol, practically insoluble in fatty oils. Trihydrate amoxicillin shows the highest stability in an aqueous solution of $\mathrm{pH}$ 3.5-5.5 [18]. On the other hand, amoxicillin sodium salt is very easily soluble in water, rather poorly soluble in anhydrous ethanol, showing the highest stability at $\mathrm{pH}$ 8.0-10.0 [18]. Potassium clavulanate in the composition of the injectable preparation is a factor limiting its stability [17]. Potassium clavulanate is a hygroscopic substance, easily soluble in water, poorly soluble in $96 \%$ ethanol, stable at $\mathrm{pH}$ 5.5-8.0 [18].

Table 1 Amoxicillin (Augmentin) content found in vaginal suppositories after a lapse of 7 and 14 days from the moment of their preparation.

\begin{tabular}{llllllll}
\hline \multirow{2}{*}{ Time } & Amoxicillin content & \multicolumn{4}{c}{ Control sample } & \multicolumn{2}{c}{ Hydrolysed sample } \\
\cline { 2 - 7 } & {$[\%]$} & $* A[\mathrm{ml}]$ & S.D. & Coefficient of variation & ${ }^{* A}[\mathrm{ml}]$ & S.D. & Coefficient of variation \\
\hline 7 days & 104,77 & 11,47 & 0,13 & $1,14 \%$ & 5,01 & 0,25 & $4,94 \%$ \\
14 days & 102,64 & 11,35 & 0,13 & $1,13 \%$ & 5,03 & 0,41 & $8,21 \%$ \\
\hline
\end{tabular}

*A - the mean number of solution sodium tiosulphate used to titrate of the iodine surplus [ml]

S.D.-standard deviation $\mathrm{n}=6$. 


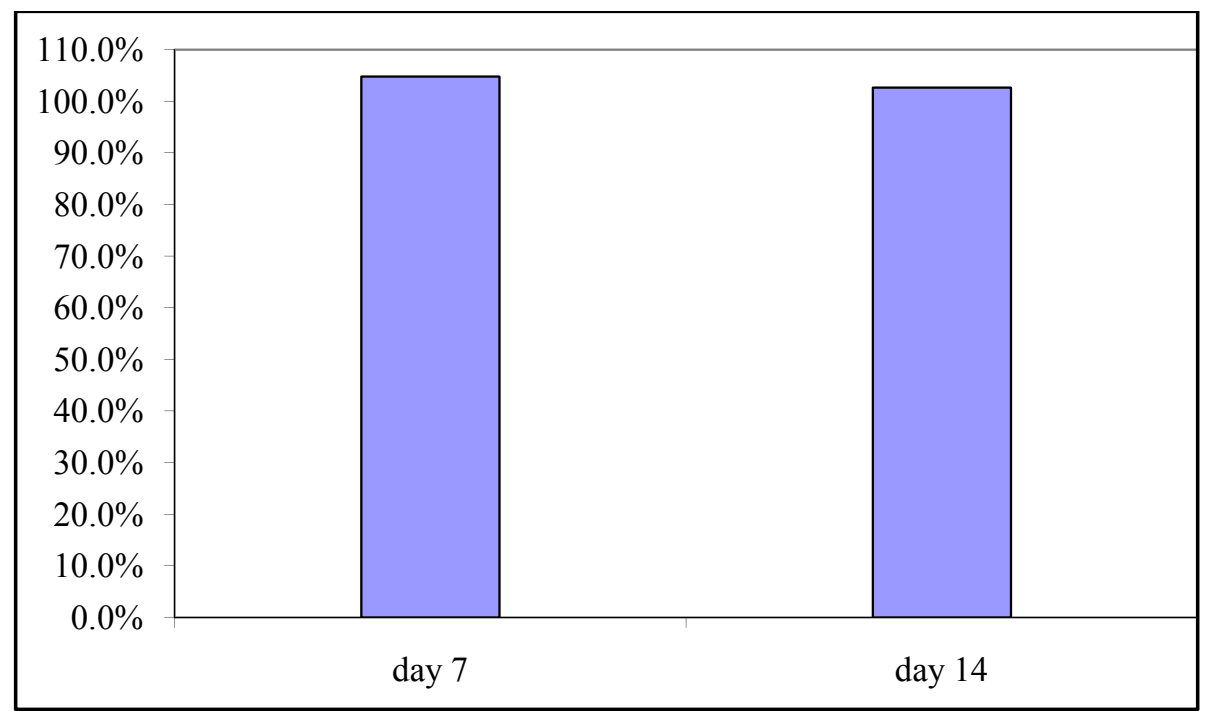

Fig. 1 Graph showing the determined amoxicillin (Augmentin) content in vaginal suppositories after a lapse of 7 and 14 days from the moment of their preparation.

Table 2 The amoxicillin (Augmentin) content in compounded ointments nos. 1, 2 and 3 after a lapse of 7 days from the moment of their preparation.

\begin{tabular}{lllllrll}
\hline \multirow{2}{*}{ Oitment number } & $\begin{array}{l}\text { Antibiotic } \\
\text { content [\%] }\end{array}$ & \multicolumn{3}{c}{ Control sample } & \multicolumn{2}{c}{ Hydrolysed sample } \\
\cline { 2 - 8 } & *A [ml] & S.D. & Coefficient of variation & $*$ A [ml] & S.D. & Coefficient of variation \\
\hline 1 & 94,72 & 13,15 & 0,16 & $1,23 \%$ & 10,61 & 0,19 & $1,80 \%$ \\
2 & 93,02 & 11,98 & 0,29 & $0,24 \%$ & 9,32 & 0,08 & $0,82 \%$ \\
3 & 88,51 & 13,38 & 0,10 & $0,72 \%$ & 10,10 & 0,18 & $1,81 \%$ \\
\hline
\end{tabular}

*A - the mean number of solution sodium tiosulphate used to titrate of the iodine surplus [ml]

S.D. - standard deviation $\mathrm{n}=6$

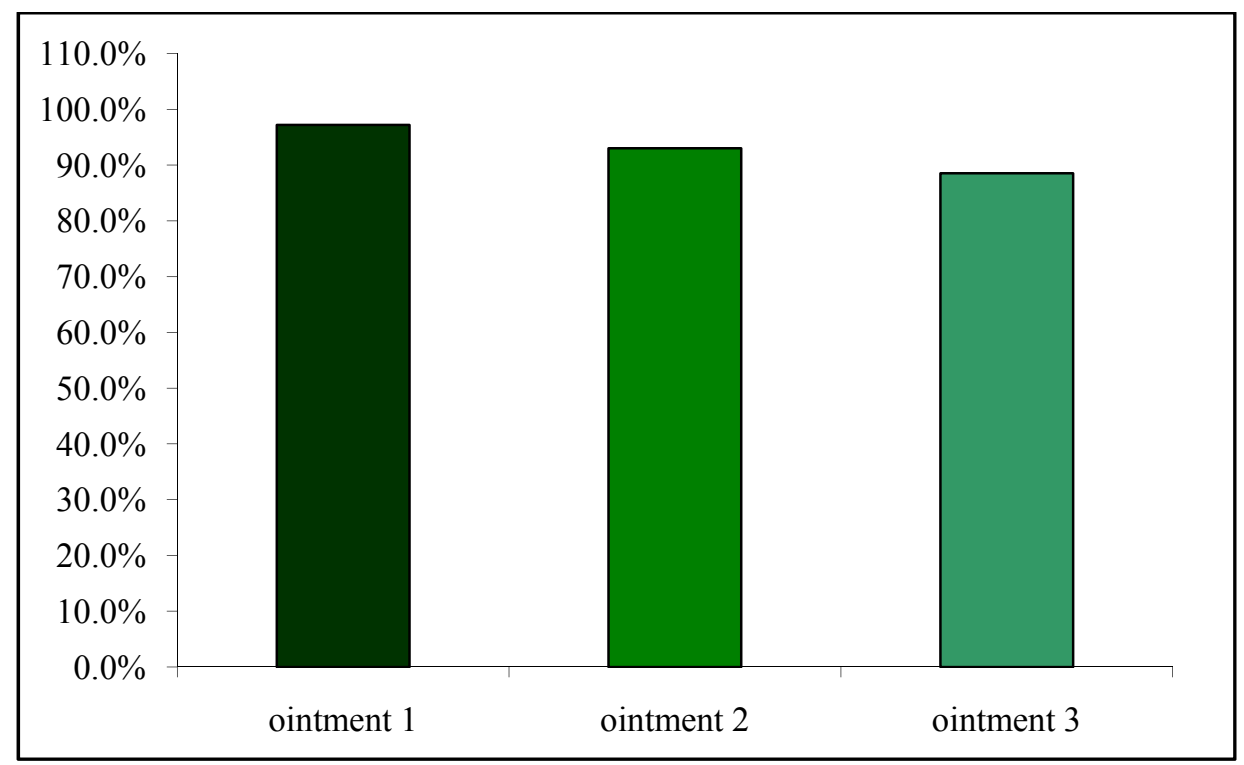

Fig. 2 Graph showing the determined amoxicillin (Augmentin) content in compounded ointments nos. 1, 2 and 3 after a lapse of 7 days from the moment of their preparation.

The conducted studies of the stability of amoxicillin, used in the form of Augmentin preparation in vaginal suppositories showed its stability during 14 days from the moment of its preparation. The mean content of amoxicillin trihydrate in the suppositories after a lapse of this time amounted to $100 \pm 2 \%$. The stability of the 
antibiotic in ointments was dependent on the type of the preparation used (Augmentin, Taromentin) as well as on the composition of ointment bases. Amoxicillin in the trihydrate form (ugmentin) was stable in anhydrous ointments. After 7 days, its mean content was approximately $95 \%$. In ointments with an addition of water the mean content of amoxicillin in the examined samples after 7 days was $93 \%$ while in ointments with an addition of a $3 \%$ solution of boric acid approximately $88 \%$. Differences in the stability of the antibiotic were related to the presence of water and a decreased $\mathrm{pH}$ of the water phase in the presence of boric acid. According to Polish Pharmacopea X, a 3\% water solution of boric acid has a $\mathrm{pH}$ of 3.8-4.8. The acidic environment thus contributed to a decrease of the stability of the antibiotic in the drug form. When amoxicillin sodium salt (Taromentin) was used in the preparation of ointments containing a 3\% solution of boric acid, the stability of the antibiotic decreased and after 7 days amounted to approximately $83 \%$ while after 14 days to approximately $67 \%$. The poorer stability of sodium amoxicillin in comparison with trihydrate amoxicillin had its source in the difference in their solubility in the water phase. Sodium amoxicillin, easily soluble in water was exposed to a larger extent to the action of the acid environment. Comparative studies of the stability of sodium amoxicillin (Taromentin) and sodium ampicillin (Ampicillin) conducted for ointments containing a $3 \%$ boric acid solution showed markedly poorer stability of sodium ampicillin. After a lapse of 7 days it was approximately $57 \%$ and after 14 days approximately $40 \%$. The difference

Table 3 Comparison of the content of amoxicillin (Taromentin) and ampicillin (Ampicillin) in ointment nos. 4 and 5 after a lapse of 7 and 14 days from the moment of their preparation.

\begin{tabular}{lllllllll}
\hline \multirow{2}{*}{$\begin{array}{l}\text { Ointment } \\
\text { number }\end{array}$} & Time & $\begin{array}{l}\text { Antibiotic } \\
\text { content [\%] }\end{array}$ & $*$ A[ml] & S.D. & $\begin{array}{l}\text { Coefficient of } \\
\text { variation }\end{array}$ & $*$ A [ml] & S.D. & $\begin{array}{l}\text { Coefficient of } \\
\text { variation }\end{array}$ \\
\hline 4 & 7 days & 82,76 & 13,59 & 0,14 & $1.00 \%$ & 13,29 & 0,08 & $0,63 \%$ \\
& 14 days & 67,24 & 13,91 & 0,02 & $0,13 \%$ & 13,66 & 0,05 & $0,38 \%$ \\
\hline 5 & 7 days & 53,02 & 13,91 & 0,10 & $0,17 \%$ & 13,14 & 0,11 & $0,80 \%$ \\
& 14 days & 38,79 & 13,90 & 0,00 & $0,00 \%$ & 13,34 & 0,05 & $0,39 \%$ \\
\hline
\end{tabular}

*A - the mean number of solution sodium tiosulphate used to titrate of the iodine surplus [ml]

S.D. - - standard deviation $\mathrm{n}=6$.

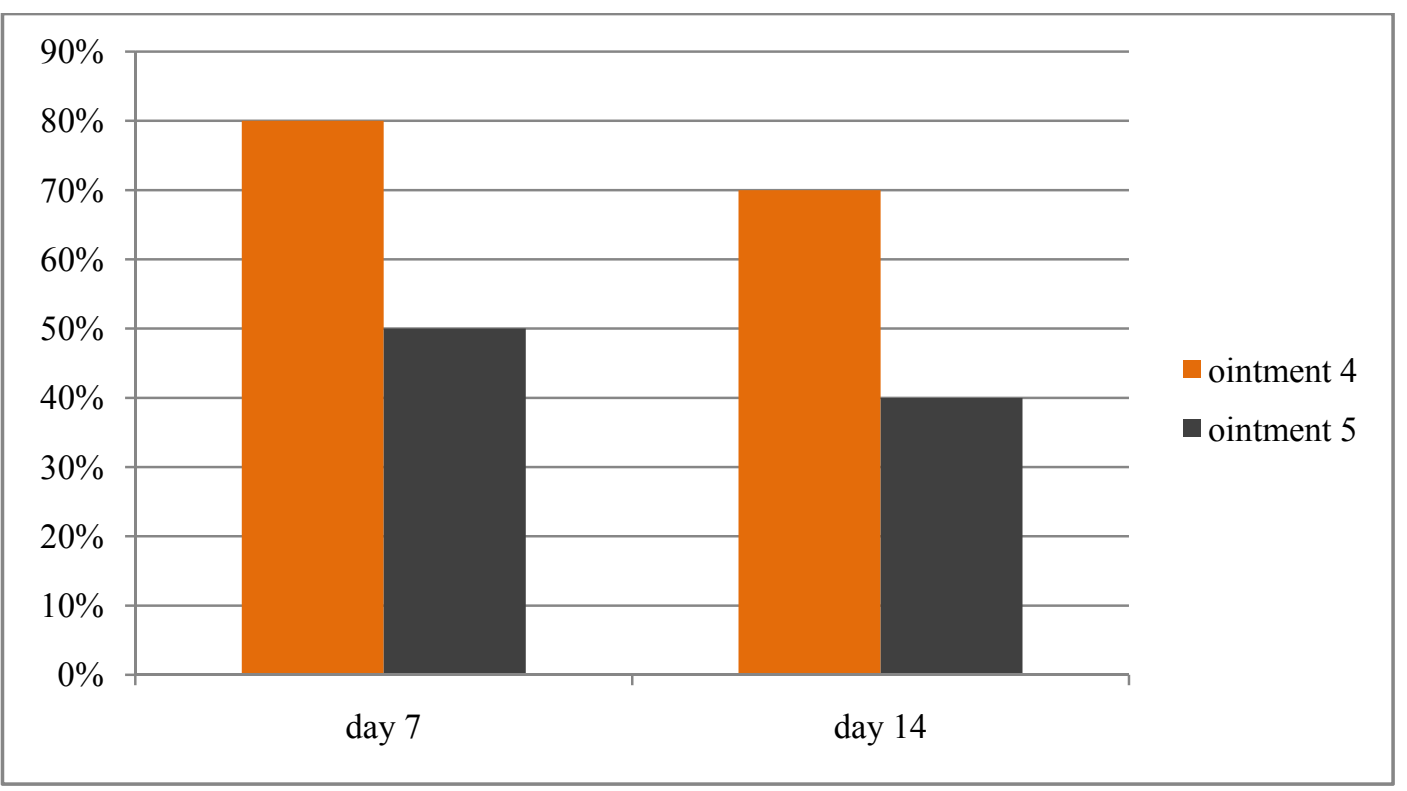

Fig. 3 Graphs showing the amoxicillin (Taromentin) content and ampicillin (Ampicillin) content in ointment nos. 4 and 5 after a lapse of 7 and 14 days from the moment of their preparation. 
in stability between sodium amoxicillin and sodium ampicillin was linked to different physicochemical properties of these antibiotics, including different sensitivity to changes in the reaction of the environment.

Amoxicillin in the form of trihydrate was stable in the suppositories and anhydrous ointments studied. Its stability decreased in hydrated ointments, in particular with the use of its sodium salt.

\section{Conclusions}

1. Amoxicillin used in the form of Augmentin preparation to obtain vaginal suppositories maintained its stability for 14 days from the moment of the preparation of a given form of the drug.

2. Amoxicillin used in the form of Augmentin preparation to obtain anhydrous ointments remained stable for 7 days from the moment of their preparation. Introduction to the ointment base of a small quantity of the water phase (water or a 3\% boric acid solution) did not affect its stability in any significant way.

3. The stability study carried out for ointments containing the water phase (a 3\% boric acid solution) showed markedly poorer stability of sodium amoxicillin being part of the composition of the preparation Taromentin in comparison with trihydrate amoxicillin being part of the composition of the preparation Augmentin.

4. Comparative studies of the stability of sodium amoxicillin (Taromentin) and sodium ampicillin (Ampicillin) carried out for ointments containing the water phase (a 3\% boric acid solution) showed markedly poorer stability of sodium ampicillin.

\section{References}

[1] Korzeniowska, K., Jabłecka, A., and Simon,K., 2008. "Side Effects of ß-lactam Antibiotics." Nowiny Lekarskie 77 (2):134-9. (in Polish)

[2] Mc Cajg, L., and Hughes, J. M. 1995. "Trends in Antimicrobiological Drug Prescribing Among Orifice Based Physicians in the United States." JAMA 273 (3): 214-19.
[3] Cars, O., Molstad, S., and Melander, A. 2001. "Variation in Antibiotic Use in the European Union." Lancet 357: 1851-3

[4] Ochocki, Z., and Stańczak, A. 2005. "Beta-lactam Antibiotics. Patr 1." Farmacja Polska LXI(1):10-21(in Polish)Hryniewicz, W., Ozorowski, T., Radzikowski, A. i wsp. 2010. Rekomendacje Postępowania w Pozaszpitalnych Zakażeniach Uktadu Oddechowego. Warszawa: Narodowy Instytut leków.

[5] Radzikowski, A. 2004. "Amoxicillin-Treatment in Outpatient Therapy.” Klinika pediatryczna 12 (2): 260-71. (in Polish)

[6] Dzierżanowska, D. 2014. "Acute Bronchitis and Pneumonia-Current Indication of Antibiotic Therapy." Medycyna po dyplomie 7 (59): 78-89. (in Polish)

[7] Hryniewicz, W., Ozorowski, T., Radzikowski, A. and all. 2010. The Ambulatory Treatment of Respiratory Tract Infection-Current Recommendations. Warsaw: Narodowy Instytut leków, Accessed December 10, 2015. http://www.antybiotyki.edu.pl/pdf/RekomendacjeA42009 .pdf. (in Polish)

[8] Mastalerz-Migas, A., and Muszyńska, A. 2011. "Amoxicillin vs Amoxicillin/clavulanateRecommendation, Effectiveness and Safety of Therapy." Medycyna i życie 4/1 (11): 6-17. (in Polish)

[9] Dzierżanowska, D. and Dzierżanowska-Fangrat, K. 2013. Guide of Antibiotictherapy, edited by A-Medica Press, Bielsko-Biala. (in Polish)

[10] Kędzia, W. 1993. "Beta-lactam Plus Beta-lactamase Blocking Agent Combinations.” Kliniczna Perinatologia $i$ ginekologia 7: 18-25. (in Polish)

[11] Przybyła, J., and Sosnowski, M. 2008. "Acute and Chronic Urinary Tract Infection-Diagnostic and Treatment." Przewodnik lekarza 4: 71-7. (in Polish)

[12] Niemiec, T., ed. 2009. Infection in Gynecology and Obstetrics Vol.1. edited by Via Medica - Wydawnictwo Medyczne, Gdańsk. (in Polish)

[13] Piątek, J. and Łabędzka-Gardy, M. 2001. “Amoxicillin-Up-Date.” Nowiny lekarskie 70 (2): 155-62. (in Polish)

[14] Ochocki, Z., and Stańczak, A. 2005. "Beta-lactam Antibiotics. Patr 2.” Farmacja Polska LXI (3): 133-146. (in Polish)

[15] Cygański, A., 1999. Chemical Methods of Quantitative Analysis, edited by Wydawnictwo Naukowo-Techniczne, Warsaw. (in Polish)

[16] Marz, K. W., Klips, H., and Lehmann, H. 1965. Die Pharmazie 20, 764. (in German)

[17] Trissel, L. A. 1992. Handbook of Injectable Drugs, 7th edition, Division of Pharmacy, University of Texas, M.D. Anderson Cancer Center, Huston, Texas, American 
Society of Hospital Pharmacists.

[18] Sweetman, S. ed. 2011. "Amoxicillin", “Ampicillin",
"Clavulanic Acid". Martindale: The Complete Drug Reference. 37th Edition. 